\section{Defining the jargon}

SIR,

What is an ethicist?

EDWARD F SHOTTER

Director of Studies

Society for the Study of Medical

Ethics

Further comment - the role of the medical ethicist

SIR,

I would like to make some comments on the 'aims and nature of the fournal of Medical Ethics' as enunciated by Lord Amulree and Prebendary E F Shotter in their reply to a letter by C G Scorer and D Johnson ( $(F M E, 4$, I06f).

The fournal seems to be in an unenviable dilemma. It is not (we are told) 'a mouthpiece for any particular moral viewpoint' and has not 'a party line on such issues as, e.g. abortion.' Yet Lord Amulree and E F Shotter in this same letter do exhibit a viewpoint and party line.

Four of these viewpoints are worthy of discussion.

I) The fournal accepts that ethics is the study of moral theory or moral philosophy'. By not defining ethics as the study of what ought or should be, it would seem that the fournal has escaped many problems. For instance, people who are for abortion and those who are against abortion will all be equally happy to read the fournal. After all, the fournal is only concerned with the methodology of those who say abortion is right or wrong. But surely this is only one logical step away from saying what is right or wrong. Thus, if one accepts the methodology by which abortion is shown to be right, one is really saying abortion is right. The only difference is that one is hiding behind this logical step. Anyone who says (for instance) 'You say abortion is right' can be answered by 'Not really, I only said that the proabortion argument is right'. It seems that the fournal is not willing to call a spade 'a spade'!
2) Following on from the above, we are told that one of the functions of the fournal is to assess 'moral theories and beliefs'. But we can never assess anything without a standard. Whenever the fournal or anyone examines something, some standard is being used, whether explicitly or implicitly. The fournal does not 'turn to the law nor for that matter to the Church for its sole authority' so what is its authority? Human reason cannot give us an authoritative answer since many different theories of mortality claim human reason as their authority. The fournal acknowledges this and says "there is no "basic standard"."

So how does the fournal assess theories and philosophies without a standard ? How can one test to see if a wall is vertical without a plumbline?

From the tone of the letter by Lord Amulree and E F Shotter, it would seem that they ruled out one thing at the start of their assessment (without a standard). That is, that there is no absolute standard. They implicitly deny a God-given revelation (in the form of the Bible) as the ultimate rule of what ought or should be.

3)The writers of the letter then consider that a 'sound moral judgement will only result where there is both knowledge and a freedom of choice'. This statement seems to imply that there is such a thing as a good moral judgement. Therefore there are right and wrong judgements. But how can one say this without an authority or standard? Will just pure knowledge of the philosophies behind arguments for and against abortion help one to decide whether abortion is right or wrong? To make such a judgement on right and wrong, one needs to have accepted a method of deciding right and wrong, not just to have a knowledge of that method.

Also in this statement is an acceptance of Platonian philosophy that right knowledge will always result in right behaviour if there is freedom of choice. Thus, any wrong is behaviour is the result of faulty $\overrightarrow{0}$ knowledge or some psychological pathology. Wrong doing is regarded $\vec{\omega}$ as ignorance or illness and not sin. S This is in direct conflict with the Bible which states that man likes to do wrong and is responsible for his wrongdoing.

4) The last point is with regard to denying the place of proselytising in $\dot{\sigma}$ the study of medical ethics. Does 0 this fournal regard the study of ethics as some academic game ? Does it care whether or not abortion is murder? Does it care whether murder is wrong or not wrong? Surely if you care, you will in $\mathbb{\Phi}$ proportion to that care, try to $\overrightarrow{\mid}$ persuade others of the fact that e.g abortion is right or wrong (whateve the case may be). If you had. experienced the forgiveness of God for wrong-doing and had been shown much of the wrong-doing in yourself and the world, would you not try to win others over to your position? I do not know C G Scorer or D Johnson, but it seems that this is their position and it is certainly mine.

Finally, I would like to point out that neutrality in anything is impossible. The christian world view is so all embracing that, as Jesus said, 'He who is not with me, is against $\mathrm{Me}^{\prime}$.

To deny the authority of the Bible in one area is to deny the authority of God's revelation and those who do so are no longer neutral. GEORGE JESSUP Concord oิ

New South Wales Australia

\section{Declaration of Hawaii}

SIR,

In the June issue of the fournal of Medical Ethics you stimulated a 0 discussion about the Code of Ethics by the WPA and the background paper by Dr Clarence Blomquist. I should like to comment on these $\varrho$ papers as follows: 
I) It is questionable whether ethics has been an essential part of culture 'ever since'. More likely ethical principles seemed to be seen as necessary not before a definitive moment in the human development; therefore they seemed to be introduced as they are expressed in the Oath of Hippocrates.

2) The ethical guideline No $I^{1} I$ find misleading. The aim of psychiatry, in my view, is to prevent or to cure psychiatric diseases. The consequence of this should be, of course, health and personal autonomy and growth. However, when health, personal autonomy and growth - without referring to psychiatric disease - are to be formulated as the direct task of psychiatry, the danger of vast expansion of psychiatry will increase. Just the renunciation of a disease concept (of which ever kind) seems to be an important source for the 'total psychiatrisation of everybody and everything' which Dr Blomquist deplores in his commentary. Our experience of the last decade has shown us that in this way the psychiatrist runs into danger of being misunderstood as a social engineer, who will be made responsible, in the end, for all problems of society.

Also I mean, that not the psychiatrist but the politician is primarily 'concerned for the common good and a just allocation of health resources'. But, and this seems important, responsible politicians should ask for advice from the psychiatrist in this respect.

3) With respect to the ethical guidelines No 5 and No 9, it could be not sufficient or it will be impossible in some cases to obtain consent only from someone close to the patient. Therefore the question of the 'Legal proxy' should be discussed.

4) The formulation "best available treatment' (guideline No 9) is questionable and should be dis- cussed. For a lot of psychiatre diseases scientifically established] 'best treatments' are not known are not generally accepted. Following this guideline, e.g., to test further the lithium prophylaxis of affectie psychoses could not have bean allowed after the vote of Blackwe and Shepherd in 1968. On the other hand a lot of such psychotherapistos or people providing 'psychotherap?' mentioned by Dr Blomquist, will be convinced that their psychotherap is the 'best available treatment'.

\section{Reference}

${ }^{1}$ World Psychiatric Association (1977) Declaration of Hawdi reprinted in fournal of Medict Ethics, 4, 2. pp 71-73. London Society for the Study of Medical Ethics, 1978.

H. HELMCHEN

Directer

Psychiatrische Klinik क् Freie Universität, Ber㩕 